\title{
Phosphorous doped hydrogenated amorphous silicon carbide films deposited by filtered cathodic vacuum arc technique
}

\author{
R. K. Tripathi, O. S. Panwar, Ajay Kumar Kesarwani and Sreekumar Chockalingam \\ Polymorphic Carbon Thin Films Group, Physics of Energy Harvesting Division, \\ C S I R-National Physical Laboratory, Dr. K. S. Krishnan Road, New Delhi-110012 (India). \\ E-mail: ospanwar@mail.nplindia.ernet.in
}

\begin{abstract}
In the present work, we report the growth and characterization of phosphorous doped hydrogenated amorphous silicon carbide (a-SiC: $\mathrm{H})$ films deposited by filtered cathodic vacuum arc technique using solid silicon target as cathode in presence of acetylene gas. The films have been characterized by $x$-ray diffraction, dark conductivity, activation energy, optical band gap, scanning electron microscopy, energy dispersive $x$-ray analysis and residual stress. The effect of are current on the properties of $\mathrm{P}$ doped a-SiC: $\mathrm{H}$ films have been studied
\end{abstract}

Index Terms - P doped a-SiC: $\mathrm{H}$, Scanning electron microscopy, X-ray diffraction, Dark conductivity, Activation energy, Optical band gap, Residual stress.

\section{INTRODUCTION}

Silicon carbide $(\mathrm{SiC})$ is a material with exceptional, physical and mechanical properties like low density, high strength, high thermal conductivity, stability at high temperature, high resistance to shocks, low thermal expansion, high refractive index, wide (tunable) band gap and chemical inertness. These promise lie in the hope of achieving better quality material at relatively low manufacturing costs. The a-Si: $\mathrm{H}$ and a-SiC: $\mathrm{H}$ type of thin film photovoltaic (PV) technology is experiencing a dramatic growth curve worldwide and offers a obliging business opportunity in power generation and building integrated solution. Cost, product maturity, excellent reliability and availability of product in lager volume are all reasons for a-Si to become the most popular of the thin film technologies. Other thin film PV technologies includes CIGS and organic PV, which have product maturity issues and CdTe which suffer from environmental issues at end of life disposal/recycling. In particular, a-SiC: $\mathrm{H}$ has inspired technological interest due to the possibility of tailoring its physical properties to suit different applications by varying the relative composition of constituent atoms. Their application may range from protective layer of solar cell both crystalline and thin films to microelectronic nanomechanical devices [1] and from passivation layer [2] to lithium ion batteries [3]. Silicon carbide is also used as substrate in catalyst free growth of graphene by many researchers [4]. Hybrid silicon carbon nanostructure composite are used as anode for lithium ion batteries by Chen et al [5]. Phosphorus-doped amorphous silicon carbide (a-SiC: $\mathrm{H})$ also demonstrated the ability to passivate c-Si substrates and highly doped n-type emitters in solar cells [2]. Hydrogenated amorphous silicon carbide (a$\mathrm{SiC}: \mathrm{H})$ provides excellent electronic surface passivation for crystalline silicon solar cells. Some new form of $\mathrm{SiC}$ thin film with different silicon and carbon content and different silicon and carbon nanostructures are potential candidate for optoelectronics materials used in solar cells [6]. Amorphous $\mathrm{SiC}$ thin film has been used in terms of stability, higher mobility, life time and diffusion length in mircomorph tandem solar cells.

The conventional process for the growth of silicon carbide films are plasma enhanced chemical vapor deposition (PECVD) and hot wire chemical vapor deposition (HFCVD) $[7,8]$ techniques. Relatively thin $\mathrm{SiC}$ can be formed by the process of carbonization in which silicon surface is exposed to amorphous carbon (a-C) containing precursor at high temperature and is converted into $\mathrm{SiC}$. In the conventional process for the growth of $\mathrm{SiC}$ thin film, gas mixture of $\mathrm{SiH}_{4}$ and $\mathrm{CH}_{4}$ are used and for the doping purpose of $\mathrm{SiC}$ film, $\mathrm{B}_{2} \mathrm{H}_{6}$ and $\mathrm{PH}_{3}$ gases are used. These gases are very toxic and hazardous. We report a new and simple filtered cathodic vacuum arc (FCVA) technique for the growth and characterization of phosphorous doped hydrogenated amorphous silicon carbide films employing a $\mathrm{P}$ doped silicon ingot as cathode and graphite rod as anode in presence of acetylene gas. The effect of arc current has been investigated on the properties of $\mathrm{P}$ doped a-SiC: $\mathrm{H}$ films.

\section{EXPERIMENTAL DETAILS}

A filtered cathodic vacuum arc (FCVA) system has been used to deposit phosphorous doped hydrogenated amorphous silicon carbide (P doped a-SiC: $\mathrm{H}$ ) thin film. The DC arc supply used was capable of delivering arc current up to $200 \mathrm{~A}$. The FCVA process is based on striking the arc (arc voltage of $35-40 \mathrm{~V}$ with an arc current of 30-200A between two electrodes. One electrode is phosphorus doped silicon ingot of (resistivity $0.55 \Omega \mathrm{cm}$ ) $50 \mathrm{~mm}$ diameter and $5 \mathrm{~mm}$ thickness as cathode (purity $99.999 \%$ ), which works as silicon source in order to deposit thin film. Second electrode is a retractable high purity graphite rod as a striker. Prior to the deposition, the chamber is evacuated to a base pressure of around $\sim 10^{-6}$ mbar by the use of turbo molecular and rotary pump combination and then high purity acetylene gas is introduced in the chamber which is used as carbon source precursor. The deposition of $\mathrm{P}$ doped a-SiC: $\mathrm{H}$ thin films was carried out at acetylene partial pressure of $5.4 \times 10^{-2}$ mbar on 7059 glass and silicon substrates placed at a distance of $35 \mathrm{~cm}$ away from the cathode. Linear magnetic filter has been used to remove the 
macro particles generated due to the arc plasma and a magnetic field of $\sim 350 \mathrm{G}$ was achieved inside the duct. The films are deposited sequentially for $5 \mathrm{sec}$ and then cooled for $50 \mathrm{sec}$. The thickness of the P-doped a-SiC: $\mathrm{H}$ film achieved at arc current of 30-100 A is found to be in the range $120 \pm 15$ $\mathrm{nm}$ as measured by Talystep (Rank Taylor and Hobson) thickness profiler. The X-ray diffraction experiments of the films was carried out by Philips X'Pert PRO PANanalytical diffractometer using a $\mathrm{CuK}_{\alpha}(1.54 \AA) \mathrm{x}$-ray source in the scanned region of $10^{\circ}-60^{\circ}$. A scanning step of $0.02^{\circ}$ is used at a time of $1 \mathrm{sec}$ per step. The surface morphology of the Pdoped a-SiC: $\mathrm{H}$ film were analyzed by SEM (Leo Electron Microscope -model no. LEO 440). The electrical conductivity is measured in coplanar structure and the value of optical band gap $\left(E_{g}\right)$ is calculated using Tauc's expression. The residual stresses (S) in the films were evaluated (FSM Frontier Semiconductor (USA) instrument) using curvature method by using Stoney's equation [9].

$$
\mathrm{S}=\frac{\mathrm{E} t_{s}^{2}}{6(1-v) t_{f}}\left(\frac{1}{R}-\frac{1}{R_{0}}\right)
$$

where E and $v$ are Young's modulus and Poisson's ratio of the substrate, respectively; $t_{s}$ and $t_{f}$ are the substrate thickness and the film thickness, respectively; $R_{0}$ and $R$ the radius of curvature of the substrate before and after film deposition. The radius of curvature $R_{0}$ and $R$ of the substrate and the films have been evaluated.

\section{RESULTS \& DISCUSSIONS}

The deposition rate of $\mathrm{P}$ doped a-SiC: $\mathrm{H}$ films achieved was found to be $50-60 \mathrm{~nm} / \mathrm{min}$ which is quite high in comparison to the PECVD grown P doped SiC: H film [8]. Fig. 1 shows X-ray diffraction of $\mathrm{P}$ doped a-SiC: $\mathrm{H}$ film

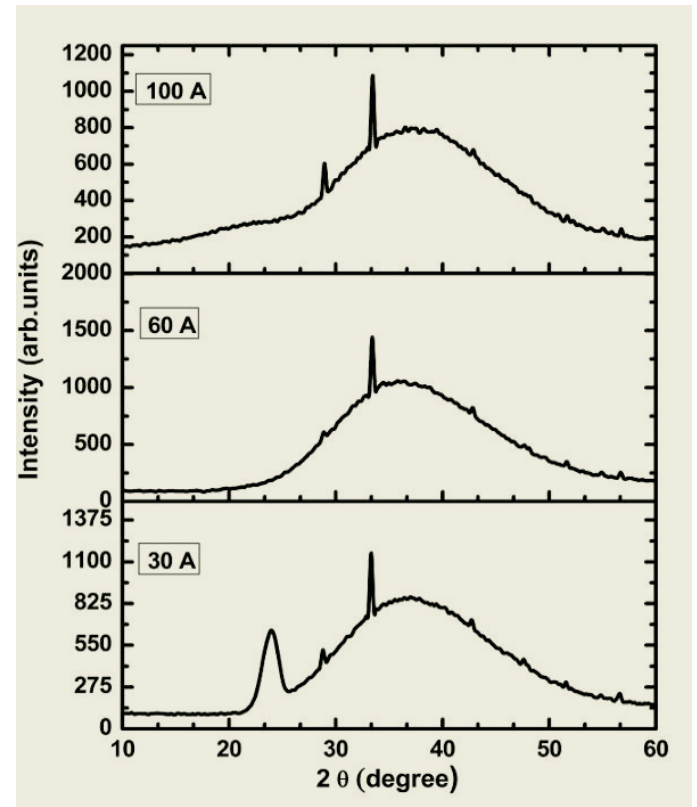

FIG.1. Typical X-ray diffraction patterns of P doped a-SiC: $\mathrm{H}$ films deposited at different arc currents. deposited at different arc currents. XRD pattern shows broad hump at $37^{\circ}$ with sharp peaks at $33.4^{\circ}$ and $28.5^{\circ}$, which reveals amorphous nature of silicon carbide, crystalline silicon carbide and silicon substrate, respectively [10]. At all the arc currents, we get this amorphous and crystalline coexisting polymorphic silicon carbide phase in the films. XRD spectra of the film deposited at low arc current of 30 A shows that amorphous carbon/silicon and polymorphic silicon carbide phase are separately nucleated whereas in the films deposited at $60 \mathrm{~A}$ arc current, the amorphous hump normally observed at $24^{0}$ disappears and in films deposited at $100 \mathrm{~A}$ arc current a shoulder at $24^{0}$ starts growing. The crystallite size (d) from sharp reflection at $33.4^{0}$ due to the interface of $\mathrm{P}$ doped a-SiC: $\mathrm{H}$ film and $\mathrm{Si}$ wafer is calculated from the well known Scherrer formula expressed as:

$$
\mathrm{d}=(0.9 \lambda) /(\beta \cos \theta)
$$

where, $\lambda$ is the wavelength of $\mathrm{X}$-ray radiation, $\beta$ is full width at half maximum of XRD peak at diffraction angle $\theta$. The crystallite size of $\mathrm{SiC}$ crystallites calculated from the Scherrer formula is found to be about $30-32 \mathrm{~nm}$. Therefore, one can elucidate that when the arc current was $30 \mathrm{~A}$, the film growth appears to be different amorphous phase of carbon/silicon and silicon carbide because of low surface diffusion of the species (ions, atoms) on the substrate. With increasing arc current during the growth of the film, the species find the energetically favorable sites for the nucleation of interface of a-SiC: $\mathrm{H}$ films. Vacuum arc produces a high temperature at the cathode surface and the evaporation of source material into a form of plasma plume. Then, the plasma plume expands in vacuum, and reaches a substrate surface to condense into thin films. The deposition process of FCVA consists of plasma generation, transformation, and condensation. Therefore, the arc current could greatly influence the properties of the deposited films.

Figure 2 shows the SEM images of $\mathrm{P}$ doped a-SiC: $\mathrm{H}$ films deposited at different arc currents of (a) $30 \mathrm{~A}, 60 \mathrm{~A}$ and 100 A. It is evident from the micrographs that there are smooth surfaces in some cases with planar appearance but with some spherical particles scattered on the surface. These particles might have been ejected from the target due to the surface heating with the subsequent fusion of the surface. The elemental concentrations of $\mathrm{P}$ doped a-SiC: $\mathrm{H}$ films deposited at different arc currents have been evaluated from the energy dispersive $x$-ray analysis (EDAX) which are summarized in Table 1. There are no impurities present in film except silicon, carbon and phosphorus. The concentration of silicon and

TABLE 1. Elemental concentration evaluated from EDAX of $P$ doped a-SiC: $\mathrm{H}$ film deposited at different arc currents.

\begin{tabular}{lccc}
\hline \hline $\begin{array}{l}\text { Element/ } \\
\text { Arc current }\end{array}$ & $30 \mathrm{~A}$ & $60 \mathrm{~A}$ & $100 \mathrm{~A}$ \\
\hline Carbon (at. \%) & 11.6 & 28.1 & 21.2 \\
Silicon (at. \%) & 88.3 & 71.8 & 78.6 \\
$\begin{array}{c}\text { Phosphorous } \\
\text { (at. \%) }\end{array}$ & $\leq 0.1$ & $\leq 0.1$ & $\leq 0.1$ \\
\hline \hline
\end{tabular}



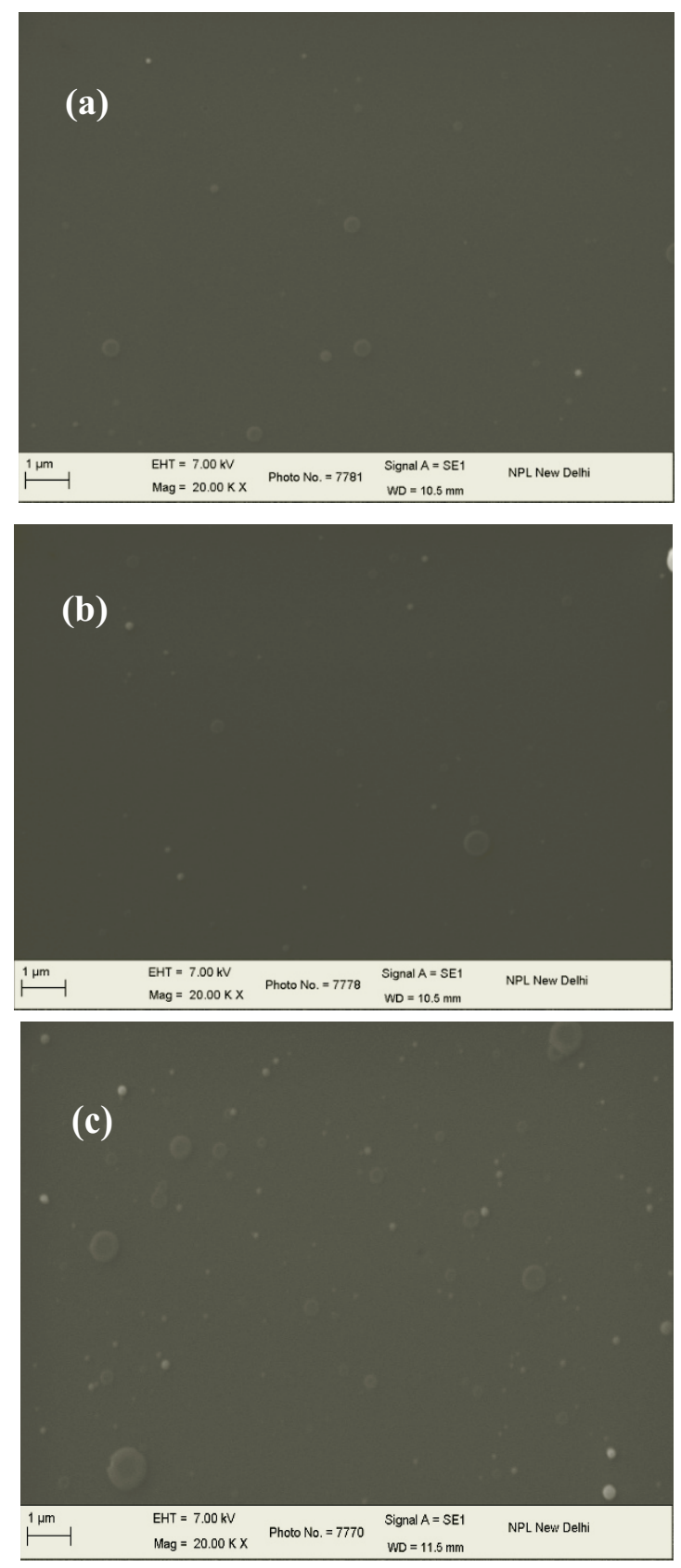

FIG.2. The typical SEM image of P doped a-SiC: $\mathrm{H}$ films deposited at different arc current of (a) $30 \mathrm{~A}$, (b) $60 \mathrm{~A}$ and (c) $100 \mathrm{~A}$

carbon evaluated from the spectra in the films deposited at 30 A arc current is found to be 88.3 at. $\%$ and 11.6 at. \%, respectively. With the increase of arc current to $60 \mathrm{~A}$, the carbon concentration in the a-SiC: $\mathrm{H}$ increases to 28.1 at. \% and silicon concentration decrease to 71.8 at. \%. At arc current of $100 \mathrm{~A}$ the carbon content in the a-SiC: $\mathrm{H}$ is reduced to 21.2 at. $\%$ and silicon concentration is increased to 78.6 at. $\%$. The $\mathrm{P}$ content in all films is found to be less than 0.1 at. $\%$. Fig. 3 shows the variation of dark conductivity $\left(\sigma_{D}\right)$ versus inverse of temperature for the $\mathrm{P}$ doped a-SiC: $\mathrm{H}$ thin films grown at different arc currents. It is evident from the figure that the variation of $\sigma_{\mathrm{D}}$ is a thermally activated process that follows a relation of the form:

$$
\sigma_{\mathrm{D}}=\sigma_{0} \exp (-\Delta \mathrm{E} / \mathrm{kT})
$$

where $\sigma_{0}$ is the conductivity pre exponential factor, $\Delta \mathrm{E}$ is the activation energy and $\mathrm{k}$ is the Boltzmann constant. Fig. 4

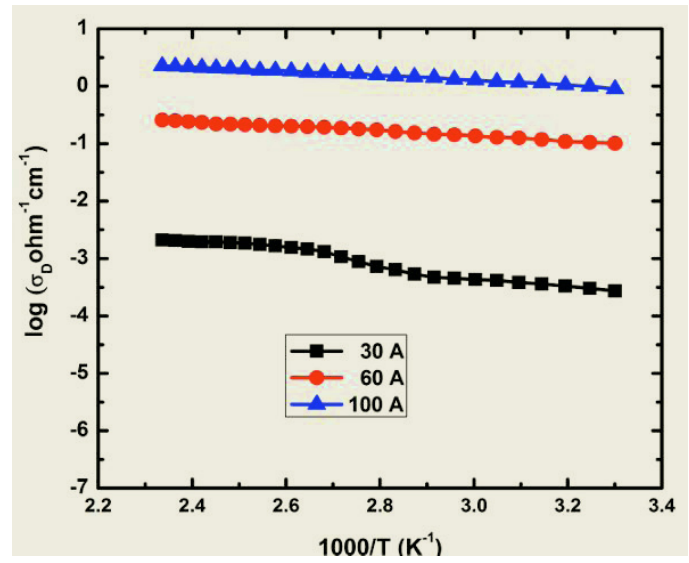

FIG.3. Variation of dark conductivity vs inverse of temperature of $\mathrm{P}$ doped a-SiC: $\mathrm{H}$ thin films deposited at different arc currents.

shows the variation of $\sigma_{\mathrm{D}}, \Delta \mathrm{E}$ and $\mathrm{E}_{\mathrm{g}}$ of $\mathrm{P}$ doped a-SiC: $\mathrm{H}$ thin films versus arc currents. It is evident from the figure that the values of $\sigma_{\mathrm{D}}$ increase from $2.7 \times 10^{-4} \mathrm{ohm}^{-1} \mathrm{~cm}^{-1}$ to $0.89 \mathrm{ohm}$ ${ }^{1} \mathrm{~cm}^{-1}$ and those of $\Delta \mathrm{E}$ decrease from 0.21 to $0.08 \mathrm{eV}$ with the increase of arc current from $30 \mathrm{~A}$ to $100 \mathrm{~A}$. The value of $\mathrm{E}_{\mathrm{g}}$ in $\mathrm{P}$ doped a-SiC: $\mathrm{H}$ is found to be $2.2 \mathrm{eV}$ which increases to 2.4 $\mathrm{eV}$ in the film deposited at $60 \mathrm{~A}$ arc current and it becomes $1.9 \mathrm{eV}$ in the film deposited at $100 \mathrm{~A}$ arc current. The values of $\sigma_{D}$ and $\Delta \mathrm{E}$ of $\mathrm{P}$ doped a-SiC: $\mathrm{H}$ films obtained in the

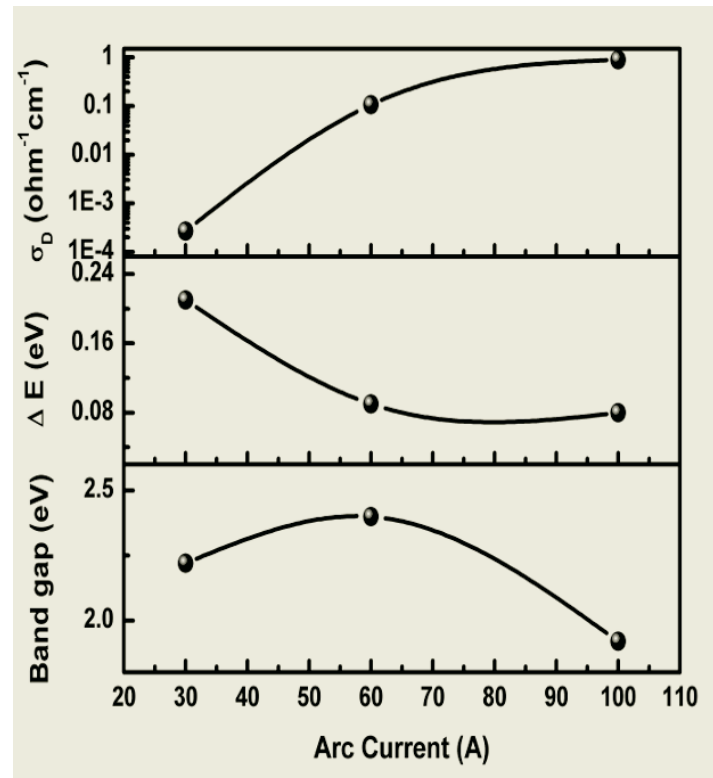

FIG.4. Variation of band gap, $\Delta \mathrm{E}, \sigma_{\mathrm{D}}$ of $\mathrm{P}$ doped a-SiC: $\mathrm{H}$ film versus arc current. 
present study using FCVA technique are found to be consistent with the values of $\sigma_{\mathrm{D}}\left(10^{-3}-10^{-2} \mathrm{ohm}^{-1} \mathrm{~cm}^{-1}\right)$ and $\Delta \mathrm{E}$ (0.13-0.06 eV) of $\mu \mathrm{c}-\mathrm{SiC}$ : $\mathrm{H}$ films deposited by VHF PECVD [8].

The increase of $\sigma_{\mathrm{D}}$ is accompanied with the decrease of $\Delta \mathrm{E}$ with the increase of arc current used in the deposition of $\mathrm{P}$ doped a-SiC: $\mathrm{H}$ films. This indicates that either efficient doping is taking place which gives rise to shift of Fermi level towards the conduction band or crystallinity in the film is increasing. In the present case, use of high arc current increases the ionization process at arc spot that increases the energy of atoms and ions ejected. Furthermore, these atoms and ions having high energy increases the rate of ionization of $\mathrm{C}_{2} \mathrm{H}_{2}$ gas, which create proper bond formation in films and provides extra charge carrier for conduction. The increase of $\mathrm{E}_{\mathrm{g}}$ in $\mathrm{P}$ doped a-SiC: $\mathrm{H}$ film deposited at $60 \mathrm{~A}$ arc current is correlated with the increase of carbon concentration and decrease of silicon concentration and beyond $60 \mathrm{~A}$ arc current the value of $E_{g}$ decreases due to the reduction in the value of carbon content incorporated in the a-SiC: $\mathrm{H}$ film. Further work is in progress.

Fig. 5 shows the variation of residual stress of film versus arc current used in the deposition of $\mathrm{P}$ doped a-SiC: $\mathrm{H}$ films. Residual stress (S) in P doped a-SiC: $\mathrm{H}$ thin film is considered to be an intrinsic property, which depends on the bonding environment of the deposited film. It has been observed that the excess of residual stress restricts the heteronucleation on foreign substrates and lowers the adhesion of the films with the substrates, which may result in their limited device applications. Residual stress (S) present in the film is found to be compressive in nature. The value of $\mathrm{S}$ is $3.3 \mathrm{GPa}$ for film deposited at $30 \mathrm{~A}$ arc current. It is found that $\mathrm{S}$ continuously decreases with the increase in arc current and the lowest value of $\mathrm{S}$ is $0.5 \mathrm{GPa}$ for films deposited at $100 \mathrm{~A}$ arc current. At higher arc current the ion energy is higher, $\mathrm{S}$ is relaxed as the atoms penetrate more deeply and induces knock-on-collisions due to which underlying atoms get even deeper. Thermal spike model [11] about the $\mathrm{S}$ of a-C films is valid, according to which local heating and immediate chilling occurs at low ion energy that leads to high $\mathrm{S}$ in films but at higher ion energy the atoms create a large region to flow and reduced value of $\mathrm{S}$ obtained

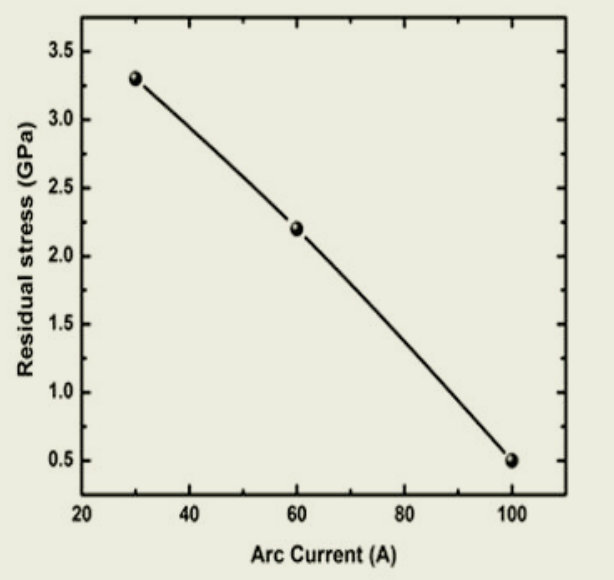

FIG.5. Variation of residual stress of P doped a-SiC: $\mathrm{H}$ thin films versus arc currents

\section{CONCLUSIONS}

In brief, phosphorus doped a-SiC: $\mathrm{H}$ films have been deposited by a simple filtered cathodic vacuum arc technique at different arc currents. In this process, no toxic and hazardous gases like $\mathrm{SiH}_{4}, \mathrm{PH}_{4}$ are used in the deposition of $\mathrm{P}$ doped a- SiC: $\mathrm{H}$ film and this is a high growth rate process. The maximum $\mathrm{C}$ content incorporated in the film deposited at $60 \mathrm{~A}$ arc current is found to be 28.1 at.\%. The XRD patterns show that the films deposited are dominantly amorphous in nature with crystalline interface of $\mathrm{SiC}$ films. The crystallite size of the films grown was around $30-32 \mathrm{~nm}$. The values of $\sigma_{\mathrm{D}}$ increases from $2.7 \times 10^{-4} \mathrm{ohm}^{-1} \mathrm{~cm}^{-1}$ to $0.89 \mathrm{ohm}^{-1} \mathrm{~cm}^{-1}$ and those of $\Delta \mathrm{E}$ decreases from 0.21 to $0.08 \mathrm{eV}$, respectively and $\mathrm{E}_{\mathrm{g}}$ vary from $1.9-2.4 \mathrm{eV}$ with the increase of arc current from $30 \mathrm{~A}$ to $100 \mathrm{~A}$. The values of $\sigma_{\mathrm{D}}$ and $\Delta \mathrm{E}$ of P doped a-SiC: $\mathrm{H}$ films obtained are found to be consistent with the values of $\sigma_{\mathrm{D}}\left(10^{-3}-10^{-2} \mathrm{ohm}^{-1} \mathrm{~cm}^{-1}\right)$ and $\Delta \mathrm{E}(0.13-0.06)$ of $\mu \mathrm{c}-\mathrm{SiC}: \mathrm{H}$ deposited by VHF PECVD in literature. The values of $\mathrm{S}$ present in the film is found to be compressive in nature and the values $\mathrm{S}$ evaluated in the film varies from 0.5 to $3.3 \mathrm{GPa}$ and it decreases with increase of arc current.

\section{Acknowledgements}

The authors are grateful to Prof. R. C. Budhani, Director, CSIR-National Physical Laboratory, New Delhi (India) for his kind permission to publish this work. We thank to Mr. K. N. Sood for SEM micrographs and EDAX results, to Dr. V. P. S. Awana for providing XRD patterns and to Dr. Sushil Kumar for useful discussion. Mr. R. K. Tripathi is grateful to the Ministry of New and Renewable Energy, Government of India for providing financial assistant during the course of this work.

\section{REFERENCES}

[1] P. M. Sarro, Sensor and Actuators 82, 210, (2000).

[2] R. Ferre I. Martin, M. Vetter, M. Garin, R. Alcubilla, Appl. Phys. Lett. 87, 202109, (2005).

[3] J. Wang, Y. Tong, Z. Xu, W. Li, P. Yan, Y. W. Chung, Mater. Lett. 97, 37, (2013)

[4] W. A de Heer, Phys. Scr. T146, 014004, (2012).

[5] P.C. Chen. J. Xu, H. Chen, C. Zhou, Nano Res. 4, 290, (2011).

[6] P. Melinon B. Masenelli, F. Tournus, A. Perez, Nature materials, 6, 479, (2007).

[7] S. Y. Lien, K. W. Weng, J. J. Huang, C. H. Hsu, C. T. Shen, C. C. Wang, Y.S. Lin, D. S. Wuu, D. C. Wu, Current App. Phys. 11, S21S24, (2011).

[8] N. Yoshida, S. Terazawa, A. Takeuchi, N. Yoneyama, T. Morino, Z. Jun, H. Natsuhara, S. Nonomura, Phys. Sta. Sol. C, 7, 790, (2010).

[9] G. G. Stoney, Proc. Royal Soc. London Ser. A 82 172(1909).

[10] Standard data, JCPDS Card numbers 892216, 772111.

[11] C. Weissmantel, Thin Solid Films, 92, 55 (1982). 